\title{
Tingkat Partisipasi Pendamping KPH dalam Mendukung Keberhasilan Kegiatan Rehabilitas Hutan dan Lahan (RHL) di Kecamatan Blangjerango Kabupaten Gayo Lues \\ Participation Level of PKH Facilitators in Supporting the Success of Forest and Land Rehabilitation Activities (FRL) in Blangjerango District, Gayo Lues Regency \\ Rahmin ${ }^{1}$, Subhan ${ }^{1}$, dan Ryan Moulana1* \\ Program Studi Kehutanan PSDKU USK Gayo Lues Fakultas Pertanian Universitas Syiah Kuala *Corresponding author : ryanmoulana@ gmail.com
}

\begin{abstract}
Abstrak
Rehabilitasi Hutan dan Lahan (RHL) merupakan salah satu upaya strategis dan kebijakan prioritas pembangunan kehutanan yang bertujuan untuk memperbaiki dan mengembalikan fungsi kawasan hutan yang telah mengalami kerusakan. Dalam pelaksanaannya, kegiatan RHL melibatkan pendamping KPH. Diharapkan dengan keterlibatan Pendamping KPH tersebut, dapat menunjang dan meningkatkan persentasi keberhasilan kegiatan RHL. Tujuan dari penelitian ini adalah untuk mengetahui keterlibatan pendamping KPH,dalam program RHL. Berdasarkan hasil penelitian keterlibatan pendamping KPH yang ditinjau dari faktor Areal, Teknis dan Finansial menunjukan rendahnya keterlibatan Pendamping KPH tersebut dalam menunjang keberhasilan RHL Hal tersebut dapat disimpulkan dari nilai yang dikumpulkan dimana Pendamping KPH memiliki jawaban rentang nilai 1.9 sampai 2.2. Adapun faktor yang mempengaruhi rendahnya keterlibatan Pendamping KPH tersebut antara lain titik lokasi peninjauan yang cukup jauh, kurangnya perlengkapan atau peralatan khusus untuk melakukan peninjauan lokasi, keterbatasan anggaran yang dikeluarkan pihak pengelola dan keterlambatan pembayaran gaji kepada Pendamping KPH tersebut.
\end{abstract}

Kata Kunci: Pendamping, Finansial, Areal dan Teknis

\begin{abstract}
Forest and Land Rehabilitation (FLR) is one of the strategic efforts and priority policies for forestry development that aims to repair and restore the function of forest areas that have been damaged. In its implementation, FLR activities involve Forest Management Unit (FMU) facilitators. It is hoped that with the involvement of the FMU Facilitator, it can support and increase the percentage of success of RHL activities. The purpose of this study was to determine the involvement of FMU facilitators in the RHL program. Based on the results of the research on the involvement of the FMU Facilitator in terms of Areal, Technical and Financial factors, it shows the low involvement of the FMU Facilitator in supporting the success of RHL. The factors that influence the low involvement of the FMU Facilitator include the remote location of the site, lack of special equipment or equipment to conduct site inspections, limited budget issued by the manager and delays in payment of salaries to the FMU Facilitato
\end{abstract}

Keywords : Facilitato, Financial, Technical, and Areal

\section{PENDAHULUAN}

\subsection{Latar Belakang}

Kawasan hutan di Kabupaten Gayo Lues terdiri dari 554.820 ha dimana dari tahun ke tahun kasus perambahan hutan secara illegal mengalami peningkatan dan terjadinya penurunan fungsi hutan. Untuk mengantisipasi hal tersebut, diperlukan pembaharuan fungsi hutan. Rehabilitasi Hutan dan Lahan (RHL) merupakan salah satu upaya strategis dan kebijakan prioritas pembangunan kehutanan yang bertujuan untuk memperbaiki dan mengembalikan fungsi kawasan hutan yang telah mengalami kerusakan. pada pelaksanaannya, kegiatan RHL melibatkan Pendamping KPH. Diharapkan dengan keterlibatan Pendamping KPH terse123but, dapat menunjang dan meningkatkan persentasi keberhasilan kegiatan RHL. Akibat dari menurunnya fungsi dan kawasan hutan di Kabupaten Gayo Lues, maka terjadi peningkatan bencana seperti: longsor, kekeringan, kebakaran hutan, erosi, banjir bandang, ambil alih fungsi serta seringnya terjadi penebangan liar hutan. Hal ini terjadi dikawasan Kecamatan Blangjerango di Kampung Akul, seringnya terjadi penebangan hutan secara liar akan berdampak buruk terhadap flora dan fauna serta berdampak juga terhadap penduduk sekitar kawasan hutan. Terjadi 
penebangan hutan secara liar dan berlangsung dari tahun ke tahun Pemerintah Daerah dan Pemerintah pusat membentuk Rehabilitsi Hutan dan Lahan (RHL).

\subsection{Perumusan Masalah}

Rumusan masalah penelitian ini untuk melihat Tingkat Partisipasi Pendamping KPH dalam Mendukung Keberhasilan RHL di Kecamatan Blangjerango Kabupaten Gayo Lues?

\subsection{Tujuan Penelitian}

Penelitian ini bertujuan untuk mengetahui Tingkat Partisipasi Pendamping KPH dalam Mendukung Keberhasilan RHL di Kecamatan Blangjerango Kabupaten Gayo Lues?

\subsection{Manfaat Penelitian}

Penelitian ini diharapkan dapat memberikan manfaat bagi pemerintah (BPDASHL dan KPH Wilayah V) dalam meningkatkan keberhasilan program RHL dimasa mendatang dan dapat dijadikan sebagai landasan teori bagi peneliti selanjutnya serta dapat menambah wawasan dan ilmu bagi para pembaca.

\section{METODOLOGI PENELITIAN}

\subsection{Tempat dan Waktu Penelitian}

Penelitian ini dilaksanakan di Desa Akul Kecamatan Blangjerango Kabupaten Gayo Lues, terhitung mulai Bulan Juli sampai dengan Desember 2019.

\subsection{Alat dan Bahan}

Adapun alat dan bahan yang digunakan pada penelitian ini ialah :

Alat Tulis Peta Penelitian Kuesioner Tali Ukur Camera Hp Tally sheet

\subsection{Prosedur Penelitian}

Mengajukan pertanyaan kepada Pendamping KPH V tentang partisipasi mendukung Rehabilitas Hutan dan Lahan RHL.

\subsection{Metode Analisa Data}

Setelah data terkumpul kemudian dianalisa menggunakan metode analisis kualitatif. oleh karena itu, data yang diperoleh dari hasil wawancara dengan para $\mathrm{KPH}$, terhadap tingkat keberhasilan Rehabilitas Hutan dan Lahan (RHL) di Kecamatan Blangjerango Kabupaten Gayo Lues yang akan didiskusikan dengan data yang diperoleh dari KPH sehingga pada akhirnya akan ditemukan faktorfaktor yang mempengaruhi tingkat keberhasilan RHL dalam kenyataannya.

\subsection{Teknik Pengumpulan Data}

Teknik yang peneliti gunakan dalam mengumpulkan data pada penelitian ini adalah: Observasi Metode Observasi, Wawancara dan Kuesioner

\subsection{Analisis Data}

Penentuan hasil Analisis data ini menggunakan kuesioner yang berlandaskan sistem penilaian Skala Likert. Skala likert merupakan skala yang digunakan dalam penelitian survey dengan orang yang menyatakan sikap yang dikategorikan tingkat sangat setuju, setuju, kurang setuju dan tidak setuju. Tabel 1. Penilaian Skala Likert

\begin{tabular}{ccc}
\hline No & Score & Penilaian \\
\hline 1 & 4 & Sangat Setuju \\
2 & 3 & Setuju \\
3 & 2 & Kurang Setuju \\
4 & 1 & Tidak Setuju \\
\hline
\end{tabular}


Untuk mengetahui keberhasilan RHL dengan adanya peran KPH, Mantanbinmas serta Waslai dalam pelaksanaan kegiatan RHL digunakan rumus

$\mathrm{UP}=\Sigma$ Orang menjawab $\mathrm{X}$ skore yang dijawab

$$
\begin{aligned}
& \bar{X}=\frac{U P}{U t m a t} \\
& \text { Jumlah Responden .......... }
\end{aligned}
$$

\section{HASIL DAN PEMBAHASAN}

Hasil penelitian terhadap partisipasi pendamping KPH dapat dilihat pada Tabel 1, 2 dan 3, Penjelasan responden terhadap areal kegiatan RHL di Desa Akul, Kecamatan Blangjerango Kabupaten Gayo Lues, terdiri dari 9 poin yang masing-masing point memiliki tingkat peran yang berbeda-beda hal ini terlihat pada Tabel 1. Teknis kegiatan RHL yang dijelaskan yaitu peralatan yang digunakan dalam mendukung keberhasilan RHL. Hasil responden dari partisipasi pendamping KPH terhadap teknis kegiatan RHL dapat dilihat pada Tabel 2. Responden terhadap areal kegiatan RHL terdiri dari 7 poin yang masing-masing point memiliki tingkat nilai yang berbeda-beda. Finansial kegiatan RHL yang dipahami yaitu pengaruh aspek finansial dalam mendukung kebehasilan RHL. Hasil penjabaran finansial terhadap peran pendamping KPH terhadap Finansial kegiatan RHL dapat dilihat pada Tabel 3 yang masing-masing memiliki 7 point pertanyaan yang masing-masing point memiliki tingkat score yang berbeda-beda.

\subsection{Penilaian Pendamping KPH Terhadap Areal, Teknis dan Finansial Kegiatan Rehabilitasi Hutan dan Lahan}

Pendamping KPH bertugas mendampingi kegiatan RHL disuatu lokasi tertentu. Tugas pendamping KPH berdaarkan BPDASHL (2020), meliputi 1) meningkatkan pengetahuan masyarakat terhadap fungsi dan manfaat hutan lingkungan bagi kehidupan dan kesejahteraan masyarakat, 2) menggerakkan dan memotivasi masyarakat untuk berpartisipasi aktif dalam kegiatan pembangunan dibidang kehutanan dan wilayahnya, 3) melakukan bimbingan teknis terhadap pemohonan izin, hak atau kegiatan pembangunan dibidang kehutanan, 4) melaksanakan bimbingan teknis kepada masyarakat tentang rencana kerja tahunan, rencana kerja usaha, rencana definitif kelompok dan rencana definitif kebutuhan kelompok kegiatan pembangunan dibidang kehutanan, 5) melakukan bimbingan teknis pelaksanaan pembangunan dibidang kehutanan, 6) melakukan monitoring dan evaluasi terhadap perkembangan kegiatan pendampingan, dan 7) membuat laporan berkala secara manual dan/atau dalam jaringan (online) kepada instansi yang menetapkan sebagai pendamping.

Pendamping KPH ini bertujuan agar masyarakat berpartisipasi aktif dalam kegiatan pembangunan dibidang kehutanan. Pelaksanaan pekerjaannya, areal, teknis, dan finansial merupakan faktor-faktor yang mungkin menghambat peran seorang pendamping. Adapun pertanyaan Skala jawaban dimulai dari tidak setuju hingga sangat setuju. Berdasarkan jawaban yang diberikan, akan terlihat bagaimana partisipasi mereka dalam menjalankan tugasnya masing-masing, apakah partisipasi aktif atau tidak. 
Tabel 1. Penilaian Pendamping KPH terhadap Areal Kegiatan Rehabilitasi Hutan dan Lahan

\begin{tabular}{|c|c|c|c|c|c|c|c|c|c|c|}
\hline \multirow{3}{*}{ No } & \multirow{3}{*}{ Pertanyaan } & \multicolumn{9}{|c|}{$\begin{array}{c}\text { Derajat Analisa } \\
\text { Pendamping KPH }\end{array}$} \\
\hline & & \multicolumn{2}{|c|}{1} & \multicolumn{2}{|c|}{2} & \multicolumn{2}{|c|}{3} & \multicolumn{2}{|c|}{4} & \multirow{2}{*}{$\begin{array}{l}\text { Rata- } \\
\text { Rata }\end{array}$} \\
\hline & & $\mathrm{F}$ & $\mathrm{S}$ & $\mathrm{F}$ & $\mathrm{S}$ & $\mathrm{F}$ & $S$ & $\mathrm{~F}$ & $\mathrm{~S}$ & \\
\hline \multicolumn{11}{|c|}{ AREAL } \\
\hline 1 & $\begin{array}{l}\text { Apakah Bapak/Ibu Dilakukan peninjauan ke lokasi } \\
\text { setiap hari.? }\end{array}$ & 1 & 1 & 2 & 4 & 2 & 6 & & & 2.2 \\
\hline 2 & $\begin{array}{l}\text { Apakah Bapak/Ibu setuju dengan akses jalan menuju } \\
\text { lokasi rehabilitasi hanya bisa dilalui oleh roda } 2 . ?\end{array}$ & 3 & 3 & 2 & 4 & & & & & 1.4 \\
\hline 3 & $\begin{array}{l}\text { Menurut Bapak/Ibu setujukah Kondisi geografis } \\
\text { dilakukan penanaman RHL.? }\end{array}$ & 1 & 1 & 3 & 6 & 1 & 3 & & & 2 \\
\hline 4 & $\begin{array}{l}\text { Maenurut Bapak/ibu Lokasi penanaman RHL ini jauh } \\
\text { dari permukiman.? }\end{array}$ & 2 & 2 & 3 & 6 & & & & & 1.6 \\
\hline 5 & $\begin{array}{l}\text { Menurut Bapak/Ibu setujukah Lokasi penanaman } \\
\text { RHL dilakukan pada lokasi yang berjam-jam dari } \\
\text { tempat tinggal.? }\end{array}$ & 1 & 1 & 3 & 6 & 1 & 3 & & & 2 \\
\hline 6 & $\begin{array}{l}\text { Menurut Bapak/Ibu Dilakukan penerapan } 6 \text { kali ke } \\
\text { lokasi dalam seminggu.? }\end{array}$ & 1 & 1 & 3 & 6 & 1 & 3 & & & 2 \\
\hline 7 & $\begin{array}{l}\text { Menurut Bapak/Ibu setujukah Dilakukan penerapan } \\
\text { untuk tinggal di lokasi.? }\end{array}$ & 2 & 2 & 1 & 2 & 1 & 3 & 1 & 4 & 2.2 \\
\hline 8 & $\begin{array}{l}\text { Menurut Bapak/Ibu Responden ikut berkontribusi } \\
\text { pada RHL ini.? }\end{array}$ & & & 2 & 4 & 3 & 9 & & & 2.6 \\
\hline 9 & $\begin{array}{l}\text { Apakah Bapak/ibu setujukah Penanaman RHL hanya } \\
\text { dilakukan dekat sungai/sumber air.? }\end{array}$ & 1 & 1 & 1 & 2 & 3 & 9 & & & 2.4 \\
\hline \multicolumn{10}{|c|}{ Rata-rata jawaban Responden } & 2.04 \\
\hline
\end{tabular}

Sumber : Data Hasil Penelitian

Berdasarkan pertanyaan yang menyatakan bahwa partisipasi pendamping KPH sangat tergolong rendah, dikarenakan pada umumnya tugas para pendamping KPH tidak sepenuhnya mengikat pada poksi peninajauan lokasi, selain itu pernyataan kurang setuju tersebut dikarenakan kondisi geografis RHL yang ditanam sebagian besar lahan safana dan kawasan ternak liar sehingga memicu kerusakan pada tanaman RHL. 
Tabel 2. Penilaian Pendamping KPH terhadap Teknis Kegiatan Rehabilitasi Hutan dan Lahan.

\begin{tabular}{|c|c|c|c|c|c|c|c|c|c|}
\hline \multirow{3}{*}{ No } & \multirow{3}{*}{ Pertanyaan } & \multicolumn{8}{|c|}{$\begin{array}{c}\text { Derajat Analisa } \\
\text { Pendamping KPH }\end{array}$} \\
\hline & & \multicolumn{2}{|c|}{1} & \multicolumn{2}{|c|}{2} & \multicolumn{2}{|c|}{3} & 4 & \multirow{2}{*}{$\begin{array}{c}\text { Rata } \\
\text { rata }\end{array}$} \\
\hline & & $\mathrm{F}$ & $\mathrm{S}$ & $\mathrm{F}$ & $\mathrm{S}$ & $\mathrm{F}$ & $\mathrm{S}$ & $\begin{array}{ll}\mathrm{F} & \mathrm{S} \\
\end{array}$ & \\
\hline \multicolumn{10}{|c|}{ TEKNIS } \\
\hline 1 & apakah Bapak/Ibu perlengkapan disediakan oleh CV.? & 2 & 2 & 1 & 2 & 2 & 6 & & 2 \\
\hline 2 & $\begin{array}{l}\text { Apakah Bapak Ibu setuju Jika Ada suatu peralatan yang } \\
\text { tidak lengkap, jika kemudian anda menggunakan } \\
\text { perlatan pribadi anda? }\end{array}$ & 2 & 2 & 1 & 2 & 2 & 6 & & 2 \\
\hline 3 & $\begin{array}{l}\text { Apakah Bapak/Ibu apabila peralatan tersebut diberikan } \\
\text { perorangan.? }\end{array}$ & & & 4 & 8 & 1 & 3 & & 2.2 \\
\hline 4 & $\begin{array}{l}\text { Apakah Bapak/Ibu Jika dilakukan tata cara } \\
\text { penggunaan peralatan tersebut.? }\end{array}$ & & & 5 & 10 & & & & 2 \\
\hline 5 & $\begin{array}{l}\text { Apakah Bapak/Ibu setuju Jika dilakukan pelatihan } \\
\text { tentang kegiatan RHL dalam sebulan sekali.? }\end{array}$ & 2 & 2 & 1 & 2 & 2 & 6 & & 2 \\
\hline 6 & $\begin{array}{l}\text { Apakah Bapak/Ibu setuju jika Transportasi diberikan } \\
\text { kepada panitia dalam pengawasan.? }\end{array}$ & 2 & 2 & 1 & 2 & 2 & 6 & & 2 \\
\hline 7 & $\begin{array}{l}\text { Setujukah Bapak/Ibu jika dilakukan Bimibingan } \\
\text { terhadap kegiatan RHL.? }\end{array}$ & 3 & 3 & 2 & 4 & & & & 1.4 \\
\hline \multicolumn{9}{|c|}{ Rata-rata jawaban Responden } & 1.94 \\
\hline
\end{tabular}

Sumber : Data Hasil Penelitian

Hasil wawancara secara mendalam kepada para pendamping KPH, pendamping mengupayakan dalam menyukseskan kegiatan RHL ini dengan cara melakukan pendekatan kepada masyarakat dan bersosialisasi tentang RHL tanpa melibatkan peralatan yang mendukung dalam RHL. Pendamping KPH juga lebih bersifat mengawasi pelaksanaan program daripada ikut serta mendampingi dan membimbing kerja masyarakat. 
Tabel 3. Penilaian Pendamping KPH terhadap Finansial Kegiatan Rehabilitasi Hutan dan Lahan.

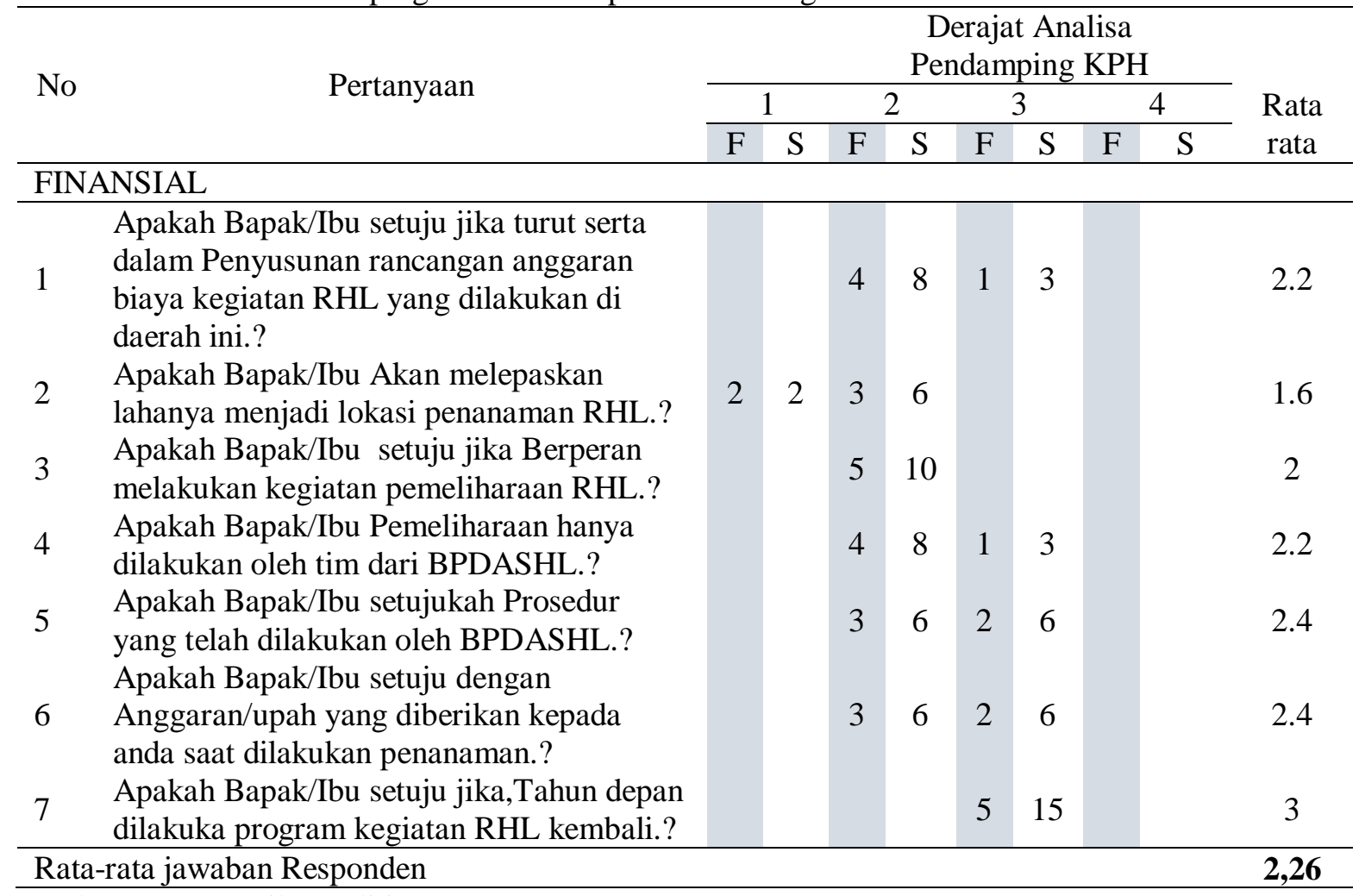

Sumber : Data Hasil Penelitian

Tabel 3 dijabarkan bahwa pengaruh aspek finansial terhadap penilaian pendamping dalam menunjang keberhasilan RHL dari rata-rata jawaban responden kurang berpengaruh terhadap meningkatkan keberhasilan RHL hal ini dikarenakn pendamping KPH tidak bekerja dengan semestinya, seperti: kurangnya sosialisasi kepada masyarakat dan motivasi masyarakat untuk berpartisipasi aktif sehinga kenyataan yang terdapat dilapangan masyarakat kurang berkontribusi dalam pemeliharaan tanaman RHL. Sebagai Primary Stakeholder KPH harusnya dalam menjaga keberhasilan program RHL yaitu Dinas Kehutanan propinsi dan Kabupaten Muba dan BPKH (Elvida dan Sylviani, 2010). Optimalisasi partisipasi kebijakan KPH dapat dilakukan dengan meningkatkan efektivitas implementasi kebijakan yang dilakukan, hal ini dikarenakan implementasi suatu kebijakan merupakan salah satu tahapan penting yang menentukan keberhasilan sebuah kebijakan publik (Ruhimat, 2013). Dwidjowijoto (2006) mengatakan 60\% keberhasilan sebuah kebijakan publik ditentukan oleh tingkat efektivitas implementasi kebijakan yang ditentukan.

\section{IV.SIMPULAN DAN SARAN}

\subsection{Simpulan} berikut:

Berdasarkan hasil penelitian yang telah dilakukan dapat diambil beberapa kesimpulan, sebagai

1. Partisipasi Pendamping KPH yang ditinjau dari aspek areal, teknis dan finansial memberikan jawaban rentang nilai 1.9 sampai 2.2. Hal tersebut menandakan bahwa partisipasi Pendamping KPH dalam kegiatan RHL sangat rendah. Pendamping KPH kurang setuju jika dilakukan peninjauan lokasi dikarenakan beberapa faktor seperti lokasi yang jauh dan akses yang sulit dijangkau, kurangnya perlengkapan dan alat penunjang untuk meninjau lokasi, terbatasnya anggaran yang dikeluarkan oleh pihak pengelola untuk melakukan peninjauan lokasi serta keterlambatan pembayaran gaji Pendamping $\mathrm{KPH}$. 


\subsection{Saran}

Perlu dilakukan penelitian lanjutan mengenai partipasi dari stakeholder lain yang juga terlibat dalam kegiatan RHL agar hasil kajian didapat lebih lengkap.

\section{DAFTAR PUSTAKA}

Dwidjowijoto, R. N. 2006. Kebijakan Publik untuk negara-negara Berkembang. PT Elex Media Komputindo. Jakarta

Elviani, Y, S., Silviana. 2010. Peran dan koordinasi para pihak dalam pengelolaan KPH. Jurnal Analisis Kebijakan kehutanan. 7 (3): 227-246.

Ruhimat, I, S. 2013. Model peningkatan partisipasi masyarakat dalam implementasi kebijakan Kesatuan Pengelolaan Hutan : Studi kasus di KPH model Kabupaten Banjar, Kalimantan Selatan. Jurnal Analisis Kebijakan Kehutanan. 10 (3): 255-267 